\title{
Investigation Of Methanol Utilization In Ci Engines
}

\author{
Ákos Bereczky ${ }^{{ }^{*}}$, Kristóf Lukács ${ }^{l}$ and Zoraze Khan ${ }^{l}$ \\ ${ }^{I}$ Budapest University of Technology and Economics (BME), Department of Energy Engineering 1111 Müegyetem rkp. 3-7, \\ Budapest, Hungary
}

\begin{abstract}
The decrease in the fossil fuel resources and more rigid emission standards make the necessity to look for new fuels and technologies. One of the possible fuels can be the different alcohols. The oxygen content of the alcohols can improve the combustion process and reduce the emission rates of incomplete combustion products. The blending methanol (M) and ethanol (E) with diesel fuel is limited by separation. This article shows the research results and analysis of two typical solutions. First are blends of stabilized rape seed methyl ester (RME) to prevent the phase separation. The tests are carried out on a conventional TDI engine (VW 1Z) at different speeds and loads. Experimental results indicate that the addition of $10 \%$ methanol to $80 \%$ Diesel and $30 \%$ of FAME blend increased the unburned hydrocarbon (THC) with $60 \%$, decreased $\mathrm{CO}$ emission with near $4 \%$ and the particulate emission (PM) with near 30\%, the NOx emissions were near the same. The other technology is the dual fuel method. In this case, different amount of methanol is injected into the intake manifold. The tests are carried out with a conventional DI engine (IVECO AIFO 8031) at constant speeds and different loads and energy ratios. Experimental results indicate that the increase of energy ratio of the methanol at full load decreased NOx emission with up to $60 \%$ and the particulate emission (PM) up to $90 \%$, while the $\mathrm{CO}$ and $\mathrm{THC}$ emissions increased extremely mainly at part loads.
\end{abstract}

\section{Introduction}

The oxygen content of the alcohols can improve the combustion process and reduce emission rates of incomplete combustion products. In addition, they modify the physical properties of the blends, decrease the density, cetane number, lower heating value (LHV), boiling point and the viscosity, but the oxygen contents of the blend increases [17, 19, 21]. The higher alcohols like different isomers of propanol and butanol can make stable blends [8, 12]. The blending methanol and ethanol with diesel fuel is limited by separation. One solution can be to utilize to blend stabilized methyl esters to prevent the phase separation $[3,7,9,10,13]$ or surfactant additive like tetrahydrofuran (THF) [2].

Other possibility is the injection of the alcohol in the intake manifold or in the combustion chamber. To inject the alcohol in the combustion chamber a high-pressure injector is needed, but the lubrication of the high-pressure injector and the atomiser is problematic. Furthermore, another atomiser system is needed in the combustion chamber which is expensive [5]. According to these considerations, the most effective solution is the multipoint injection in the intake manifold. In case of dual fuel engine, the alcohol as a primary fuel is injected in the intake manifold of the engine and the produced homogenous mixture is ignited in the combustion chamber by the injected diesel fuel as secondary fuel $[5,15,16]$. In this case the main parameter is the energy ratio:

$$
E_{r}=\frac{L H V_{p} * \dot{B}_{P}}{L H V_{p} * \dot{B}_{P}+L H V_{D 2} * \dot{B}_{D 2}}
$$

\section{Engine and test regimes}

The tests are carried out with the AVL-7030 fuel balance as fuel consumption measuring system, HORIBA MEXA-8120 F exhaust gas analyser system, and AVL 415 smoke meter.

Engine tests were carried out in Jendrassik György laboratory of Budapest University of Technology and Economics. VW- Audi diesel engine 1.9 TDI $1 \mathrm{Z}$ was used for $\mathrm{r}$ triple blend tests (D2-M-RME). Engine with an open combustion chamber (direct injection), containing a turbo compressor, an exhaust gas recirculation system (to achieve more accurate heat release results, the system was off during tests) and an electronic control unit (ECU).

\footnotetext{
${ }^{*}$ Corresponding author: bereczky@energia.bme.hu
} 
In the first step of the test, at the chosen speeds (2000, 2500, 3000 and 3500 RPM) the maximum loads were determined and the $25 \%, 50 \%$ and $75 \%$ of the maximum torque with diesel fuel (D2) were determined.

1.9 TDI engine model was created by the software AVL Boost Burn and used for analysis of heat release $\left(d Q / d \varphi_{\max }\right)$ and pressure rise $\left(d p / d \varphi_{\max }\right)$ characteristics [4]. Having the required experimental data, the software AVL Boost Burn makes these calculations relatively easy and quick.

The dual fuel tests the developed system, a M8B 160 generator is driven by an IVECO AIFO 2.9 diesel engine with direct injection. The alcohol is injected in the intake manifold of each cylinder. The installation of the injection lines needed a new intake manifold system, which was made possible by welding from patent boards and cut pieces which were suitable for the receiving of the nozzles. The fuel was atomised by the nozzles on the intake valves, avoid the condensation on wall of the intake manifold to. To regulate the combustion process the timing of the injection was resolved by modification of injection pump.

\section{Results with triple blends [results based on 18]}

Practically in the whole engine load range the BTE increased in the case of B30, $1-2 \%$ and with B30+10M 2-2.5\% respectively. The $\mathrm{NO}_{\mathrm{X}}$ increased with the $\mathrm{B} 30$ and $\mathrm{B} 30+\mathrm{M} 10$ blends, the highest change was at 3000 RPM at $25 \%$ and $50 \%$ load, $4.5-6 \%$ at full load, $0-2 \%$ at $75 \%$ load, the EDC increased the pre-injection angle with the fuel mass flow, therefore there was intensive increase (Fig. 1):

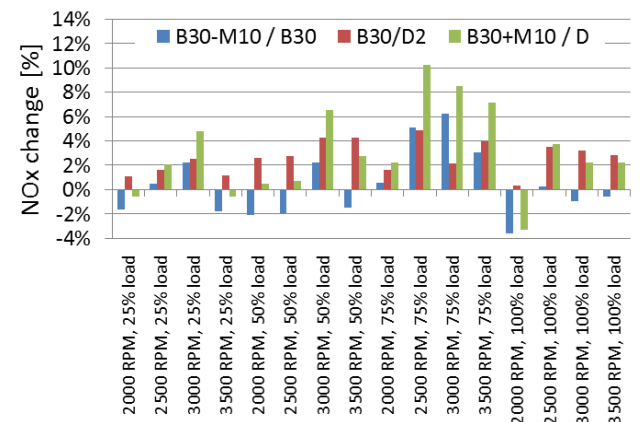

Fig. 1. The change of NOx emission comparing to D2 and B30 at different loads and speeds (results based on 18)

The distribution of the incomplete combustion products' ( $\mathrm{CO}$ and $\mathrm{HC}$ ) concentration values is ambiguous: in case of using B30, the concentration of CO was decreased mainly at 50\%-100\% loads, with methanol blend at low load (25\%) increased $10-20 \%$, at high loads deceased (Fig. 2):

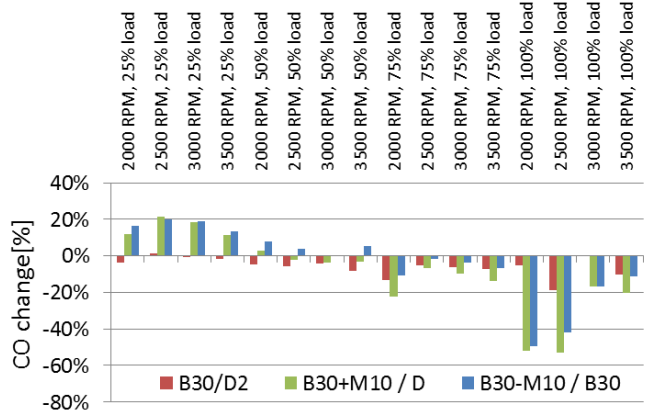

Fig. 2. The change of CO emission comparing to D2 and B30 at different loads and speeds (results based on 18)

The THC concentration values reduced by $32 \%$ in the whole load range; in case of $\mathrm{B} 30+10 \mathrm{M}$, THC values were varying in the range of -8 to $+18 \%$ through all experimental load points (Fig. 3):

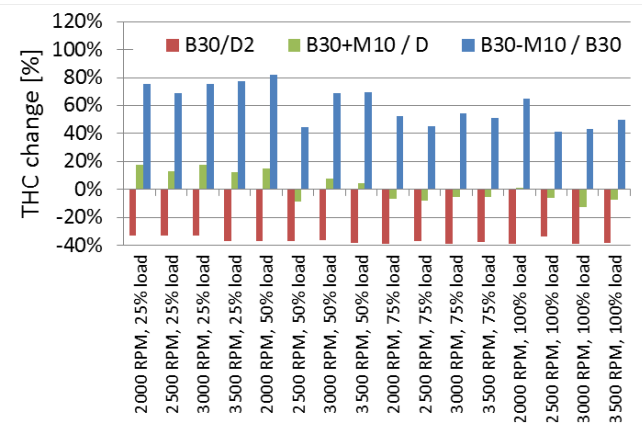

Fig. 3. The change of THC emission comparing to D2 and $\mathrm{B} 30$ at different loads and speeds (results based on 18)

The PM concentration values were reduced by $12-22 \%(\mathrm{~B} 30)$ and $28-54 \%(\mathrm{~B} 30+10 \mathrm{M})$ compared to D2 (Fig. 4):

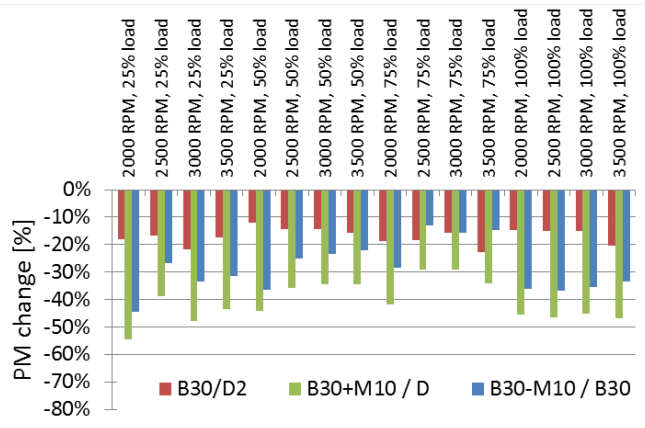

Fig. 4. The change of PM emission comparing to D2 and $\mathrm{B} 30$ at different loads and speeds (results based on 18)

Table 1 presents the averaged change of the emissions. In the case of $\mathrm{NOx}$, the averages do not include the $75 \%$ load points as mentioned the influence of the modified pre-injection was high. The methanol had low influence on the $\mathrm{NO}_{\mathrm{x}}$ [14] emission but the THC emissions increased showing the methanol influence was higher, whereas with the RME the THC emissions were decreased. Soot concentration values were reduced by more than 
$16 \%$ with biodiesel and $40.7 \%$ with $\mathrm{RME}$ methanol blend compared to D2:

\begin{tabular}{|ccccc|}
\hline $\begin{array}{l}\text { NOx } \\
\text { change } \\
{[\%]}\end{array}$ & $\begin{array}{l}\text { THC } \\
\text { change } \\
{[\%]}\end{array}$ & $\begin{array}{l}\text { CO } \\
\text { change } \\
{[\%]}\end{array}$ & $\begin{array}{l}\text { PM } \\
\text { change } \\
{[\%]}\end{array}$ \\
\hline $\begin{array}{c}\text { B30/ } \\
\text { D2 }\end{array}$ & $2.5 \%$ & $-36 \%$ & -5.8 & -16.9 \\
\hline $\begin{array}{c}\text { B30+ } \\
\text { M10/ } \\
\text { D2 }\end{array}$ & $1.8 \%$ & 1,9 & $-8.6 \%$ & -40.7 \\
\hline $\begin{array}{c}\text { B30+ } \\
\text { M10/ } \\
\text { B30 }\end{array}$ & $-0.7 \%$ & $60.4 \%$ & -3.5 & -28.5 \\
\hline
\end{tabular}

Table 1. The average change of the different emission components comparing with D2 and B30

\section{Results with dual fuel system}

At $24 \mathrm{~kW}$ loads, the maximum pressure increased from $0 \%$ to $75 \% \mathrm{Er}$, the maximum values were at $75 \% \mathrm{Er}$, but the maximum appeared later (Fig. 5). In the case of $90 \% \mathrm{Er}$, the pressure was significantly reduced and the maximum values occurred significantly later (Fig.5):

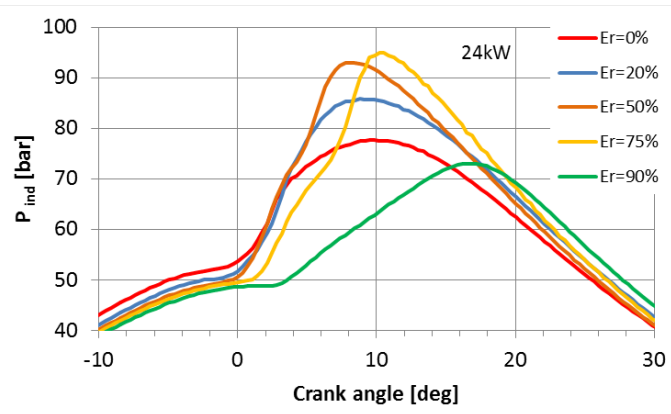

Fig. 5. The indicated pressures in the function of the crank angle at different energy rations at $24 \mathrm{~kW}$ load [16]

The effects are well visible on HRR functions (Fig.6):

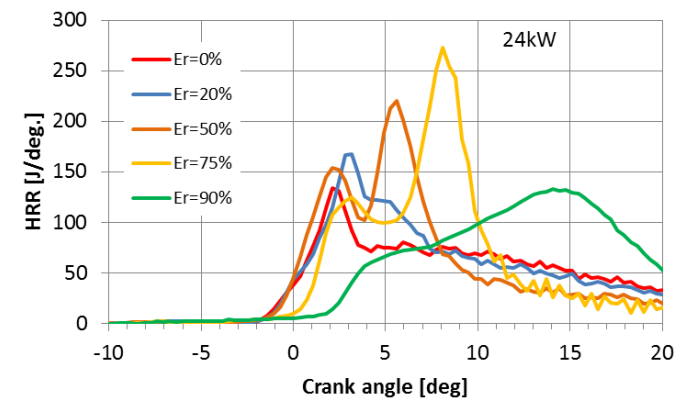

Fig. 6. The heat release rate (HRR) in the function of the crank angle at different energy rations at $24 \mathrm{~kW}$ load [16]

In the case of pure gas oil, conventional premixed - diffuse combustion phenomena can be observed, at $20 \% \mathrm{Er}$ the pre-mixed section increased to the same extent as the diffuse part of the combustion. With the further increase in methanol content (50\% Er), combustion has been significantly transformed, intense combustion of methanol started at the beginning of the pre-mixed phase and continued in the diffuse stage and reached the maximum of HRR. By further increase in methanol content $(75 \% \mathrm{Er})$, ignition delay is increased, as D2 fuel was significantly reduced, the pre-mixed phase could ignite a small amount of methanol, therefore the intense burning of methanol started later and reached its maximum in the diffusion phase. In case of $90 \% \mathrm{Er}$, combustion changes significantly. The inflammation delay increased significantly due to the heavy overflow of methanol in the combustion chamber.The $\mathrm{NO}_{\mathrm{x}}$ emissions at full load $(24 \mathrm{~kW})$ were maximum at $20 \% \mathrm{Er}$, in this case the premixed combustion was maximum and the $\mathrm{NO}_{\mathrm{x}}$ emission increased compare to D2 (Fig. 7):

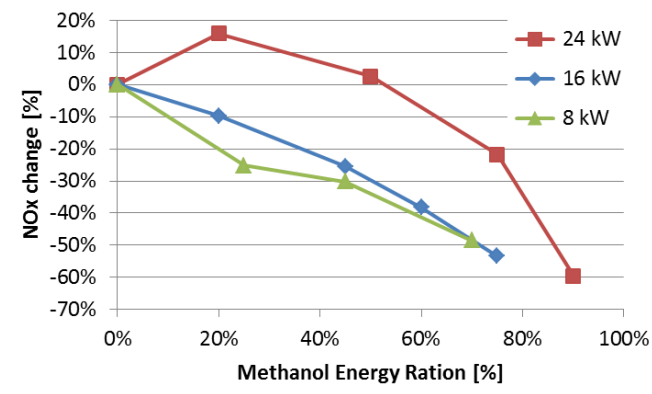

Fig. 7. The change of $\mathrm{NO}_{\mathrm{x}}$ emissions in the function methanol energy ratio (Er) at different loads (results based on 16)

With the growth of Er, the intensity of the premixed stage appeared later and the evaporation of Methanol decreased $\mathrm{NO}_{\mathrm{x}}$ emission. At part loads, the decreased fuel and increased air-to fuel ratio decreased $\mathrm{NO}_{\mathrm{x}}$ emission. The distribution of incomplete combustion products' ( $\mathrm{CO}$ and THC) concentration values increased with $\mathrm{Er}$, mainly at part loads $(16 \mathrm{~kW}$ and $8 \mathrm{~kW})$. This indicates that the quality of the methanol burning process has decreased (Fig.8-9):

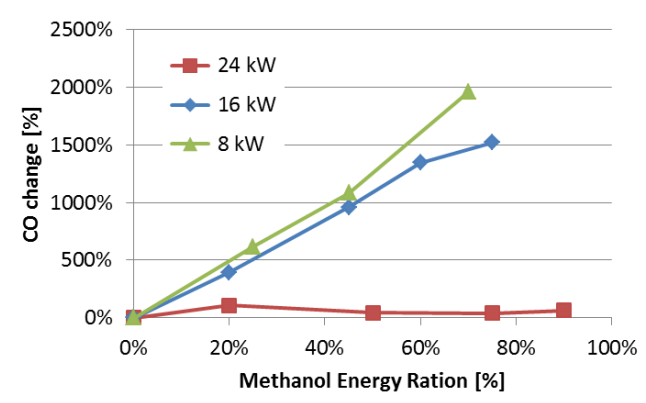

Fig. 8. The change of $\mathrm{CO}$ emissions in the function methanol energy ratio (Er)at different loads (results based on 16) 


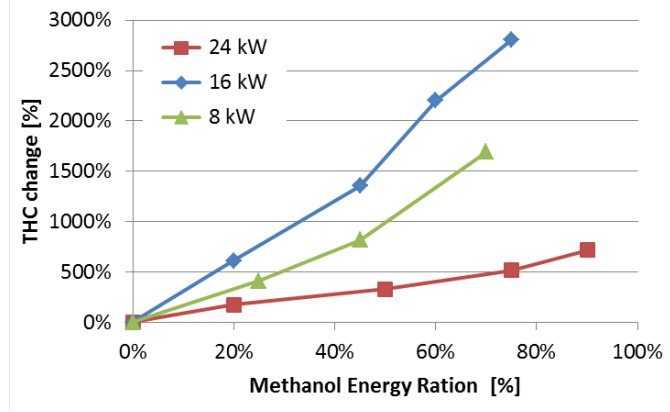

Fig. 9. The change THC emissions in the function methanol energy ratio (Er)at different loads (results based on 16)

Particle matter (PM) emissions, with increased Er, drops considerably, at full load at $90 \% \mathrm{Er}$, it is reduced to just $4 \%$ compared to D2, the primary reason for this being the decreased diesel fuel (D2) content (Fig. 10):

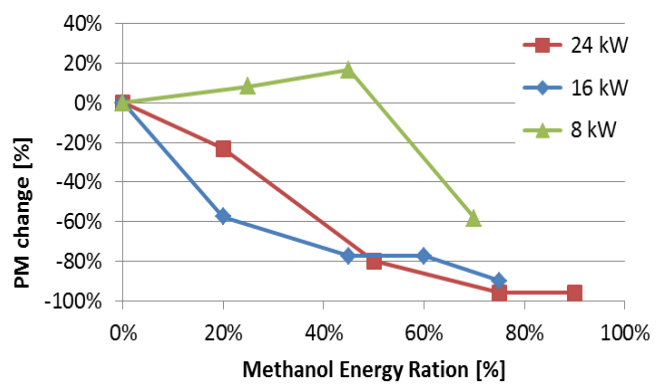

Fig. 10. The change of $P M$ emissions in the function methanol energy ratio (Er)at different loads (results based on 16)

\section{Modelling}

Modelling of the working process is very important for educational and development purposes. For problems solving we use a one dimensional system, like the AVL Boost system and the AVL FIRE CFD software package for CFD calculations. There are many possibilities for modelling the different fuel blends and dual fuel system with CFD methods $[11,16]$.

\subsection{CFD simulations}

Numerical modelling of the in-cylinder processes is low cost and less rigorous method for the analysis of performance and emission characteristics. The model studies are based on ECFM combustion model. This used code is developed based on the FV approach with the pressure based segregated solution algorithm and the SIMPLE algorithm is used for velocity and pressure coupling. ECFM model is founded on the concept of laminar flame propagation and the flame velocity and thickness are taken to be the average flame front values. Various other combinations of models are used.
Turbulence of the charge is modelled by K-zeta- $\mathrm{f}$ model, combustion for diesel by ECFM-3Z, and for dual fuel, ECFM by combining it with the diesel ignited gas engine ignition model, spray atomization by WAVE breakup and multicomponent evaporation model for spray evaporation, Extended Zeldowich and Lund flamelet models are used for modelling NOx and soot emissions respectively. With this CFD software package the combustion process of different methanol energy rations investigated (Fig. 11.).

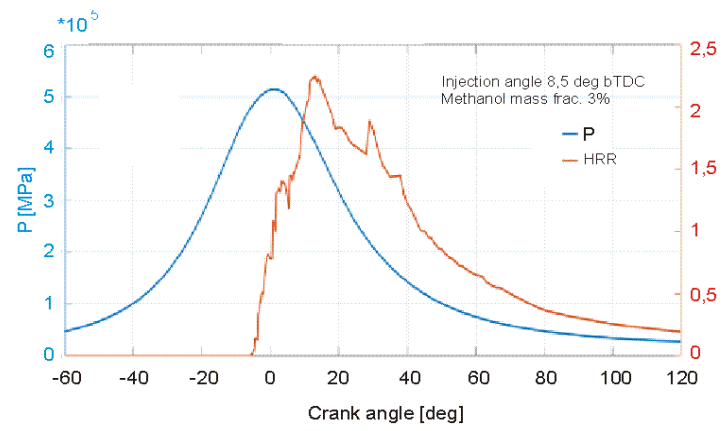

Fig. 11. Numerical calculation of HRR [J/deg*100] and pressure in the function of crank angle at $3 \%$ methanol mass fraction

The main target of present simulation work to simulate PPCI and HCCI combustion. Because at low-mid engine load range these methods can be successful to achieve low $\mathrm{NO}_{\mathrm{x}}$ and PM emissions. [20].

\section{Conclusions}

The triple blend give a possibility to decrease PM up to $40 \%$ and $\mathrm{CO}$ emission up to $9 \%$, but the $\mathrm{NO}_{\mathrm{x}}$ emission increase $(1.8 \%)$, when the BTE increased and with B30 + 10M, 2-2.5\%.

The dual fuel technology give opportunity the decrease the $\mathrm{PM}$ and $\mathrm{NO}_{\mathrm{x}}$ emission together, but the low load has problems with incomplete combustion products ( $\mathrm{CO}$ and $\mathrm{THC})$.

Authors are grateful to AVL GmbH Company for the possibilities to use their simulation software (AVL Boost).

\section{REFERENCES}

1. AVL: AVL FIRE® VERSION 2011. Combustion and Emission module. Edition 10/2011.

2. I. Barabás, A. Molea., R. Suciu. Proceedings of the 4th International Congress of Automotive and Transport Engineering (AMMA 2018). Proceedings in Automotive Engineering. Springer, (2018) 
3. I. Barabás, M. Zöldy, I. A. Todorut Oil and Natural Gas. 644: Studium Press LLC, 2015. pp. 577-606.

4. Á. Bereczky, K. Lukács, Á. Sipos, OGÉT 2015: XXIII. Nemzetközi Gépészeti Találkozó, 32-36, (2015)

5. Emőd - Tölgyesi - Zöldy: Alternatív jármühajtások, Maróti kiadó (2006)

6. G. Szabados, Á. Bereczky: PolytechnicaMechanical Engineering 59. (3) 120-125. (2015)

7. A. Jamrozik, W. Tutak, M. Gruca, M. Pyrc, Journal of Mechanical Science and Technology. 32, 6, 2947-2957, (2018).

8. A. Jamrozik, W. Tutak, M. Pyrc, M. Gruca, M. Kočiško, Fuel, 221, 329-345, 2018.

9. A. Jamrozik W. Tuta, M. Pyrc, M. Sobiepański, Environmental Progress \& Sustainable Energy, 36, pp. 1151-1163

10. T. Laza: Polytechnica-Mechanical Engineering 52. (2). 67-70. (2008)

11. K. Lukács, Z. Szurdoki, Á. Bereczky, ENELKO2013 XIV. 95-100, (2013).
12. M Zoldy, A Hollo, A Thernesz: SAE Technical Paper, 2010-01-0481

13. M Zöldy: Transport 26 (3), 303-309

14. G. Szabados, Á. Bereczky, Periodica Polytechnica Mechanical Engineering, 59(3), 120-125. DOI: 10.3311/PPme.7989. (2015)

15. W. Tutak A. Jamrozik R. Gnatowska, Thermal Science, 22, 3, 1191-1203(2018).

16. W. Tutak, A. Jamrozik, Á. Bereczky, K. Lukacs, Transport, 33(3), 633-646. (2018)

17. J. Žaglinskis, "Periodica Polytechnica Mechanical Engineering, 59(4), 169-175. DOI: https://doi.org/10.3311/PPme.8216. (2015)

18. J. Žaglinskis, K. Lukács, Á. Fuel 170. 245-253. (2016)

19. M. Zoldy, A. Torok Period. Polytech. Transp. Eng., 43, 4. 172-176 (2015),

20. H. Xiaoye, Y. Zhenyi, W. Meiping, T. Jimi, Z. Ming. Applied Energy 198, 347-359, (2017)

21. A. Rimkus, J. Matijošius, M. Bogdevičius, Á. Bereczky, Á. Török, Energy, 152, 640-651. (2018) 